\title{
Recognizing influencing factors on students' leadership trait potential
}

\author{
Azar Kafashpoor ${ }^{a}$, Amir Kariznoee ${ }^{\text {b* }}$, Mohammad Reza Hosseini Moghadam ${ }^{\mathrm{c}}$ and Mohammad Taghi \\ Sargazic $^{\mathrm{C}}$
}

${ }^{a}$ Assistant professor of Ferdowsi University of Mashhad, Iran

${ }^{b}$ M.A in industrial Management of Ferdowsi University of Mashhad, Iran

${ }^{c}$ M.A in Business Management of Ferdowsi University of Mashhad, Iran

\section{H R O N I C L E

$$
\text { A B S T R A C T }
$$

Article history:

Received January 8, 2013

Received in revised format

4 April 2013

Accepted 6 April 2013

Available online

April 72013

Keywords:

University education

Leadership trait potential

Gender
This paper presents a study to investigate the effect of university education on leadership capacity of both male and female management students of Ferdowsi University of Mashhad. The data were collected from the first and the last year students using classified sampling method. The results of 116 questionnaires analyzed using SPSS software indicate that university education had a different effect on both male and female students' leadership capacity. Comparing the results of this study with other countries shows that the role of culture should be considered as an effective factor, while evaluating and comparing students' leadership capacity among communities.

\section{Introduction}

Leadership is an art to influence subordinates in such a way that they voluntarily and willingly do the pre-specified amount of work in terms of specific objectives. Leadership includes influence and change and it is the art of managing people with others (Afjeh, 2006). Some experts consider leadership as one of the managers' duties while some others believe that leadership is something beyond management and managers are not necessarily leaders. Different people have various perceptions and different consequences appear because of a unique behavior. This complexity is not only because of people's personal characteristics but also because of the influences that different situations have on people's personality. Leadership exists in all organizations such as school, government, church, enterprise, etc. For instance, one of the features of successful managers in educational organizations is to create and to develop self-leadership among students (Mirkamali, 2009).

*Corresponding author.

E-mail addresses: amir.kariznoee@yahoo.com (A. Kariznoee) 
College students' leadership capacity is relatively a new issue, which has considered by international community since 1990 after recognizing the important role of student in the future (Dugan \& Komives, 2010). Over the last 100 years, the majority of the leadership studies have been conducted with college students as participants (Avolio, 2005).

The inadequacy of research on college student leadership impedes the success of college in developing student leadership capacity (Astin, 1999). However, the relative importance of embedding leadership development efforts within the college curriculum used to be underestimated (Karnes \& Bean 1999). During the last decade, there has been an increase interests in learning the effects of general classroom activities, such as grade-point average, class preparation and engagement and class attendance on students' personal characteristics (Tompson, 2006).

Curricular learning is self-directed, problem-centered, and collaborative. Through co-curricular learning experiences, students cultivate capacities to reflect on experiences and beliefs, work with others in pursuit of a common objective, and continually adjust to change (MacKinnon-Slaney 1993). Co-curricular learning experiences cause interactions among people from different cultural backgrounds (Astin, 1999). Campus residence and employment during college, diverse social interactions (Dugan \& Komives, 2010), athletic activity and involvement in student organizations have been empirically demonstrated to substantially correlate with college student leadership development (Komives et al., 2005).

Dunkel et al. (1989) reported that, in the United States, co-curricular involvement during college had significant impact on increasing students' leadership capacity (Dunkel et al., 1998). In Asia Pacific countries, such as Taiwan and Korea, students are usually dissuaded from participating in cocurricular activities by parents and society. They believed that co-curricular, involvement could interfere with student curricular learning and had a negative effect on students' educational outcomes (Huang \& Chang, 2004). Regarding the influence of the college, Pascarella and Terenzini (1991, 2005) argued that the college might make distinct influences on students in terms of various characteristics called conditional effects and they also discussed a case associated with gender (Pascarella \& Terenzini, 2005).

Eagly and Carli performed an investigated on effects of gender differences and reported that male and female leaders 'effectiveness to be rather different in various social contexts and evaluation approaches (Eagly \& Carli, 2007). Sax and Brayant found that male and female students could be influenced by various factors. Some researchers have also stated that the female students demonstrated lower levels of willingness compared with male students (Boatwright \& Egidio, 2003). Dugan and Komives (2010) concluded that female students were more willing to lead than men were.

According to Moghaddas Pour et al. (2012), Leadership plays an important role among five main components of management. They argued that these days many organizations attempted to resolve any existing conflicts through adapting an appropriate leadership strategy. They performed an empirical study to detect the relationship between relationship-oriented leadership style and solutionoriented strategy as well as between leadership style and conflict management. Their study distributed a questionnaire among 43 managers who were in different industries in west part of Iran. Most of the people who participated in our survey were male and they were between 25 to 30 years old. The study considered relationship between leadership style and conflict management, which includes the relationship between relationship-oriented and task-oriented leaderships with avoiding conflict management strategy, solution and control based conflict managements. The results confirmed that there was only a meaningful relationship between relationship-oriented leadership with solution-based conflict management. In other words, their survey indicated that when there was a conflict, management could handle the problem using his/her relationship and find appropriate solution to resolve any possible conflict. According to Nemati (2012), culture plays an important role on human lives and it has been in four ancient civilizations of China, Iran, Egypt and Greece. The 
civilization achievements are normally categorized in two different groups of material and immaterial. Practical experience of the material, social objective is called as a civilization and the mental aspect of spiritual experiences, spiritual and personal is called culture. Nemati presented a framework for cross-cultural management and investigated the role of government on creating adaptive culture within the society. He also explained that government must act as leadership in creating value added culture.

The proposed study of this paper attempts to understand whether university education could influence male and female student leadership capacity or not. It also investigates whether university education could impact leadership capacity in terms of gender or not. We also compare the results with other existing studies.

\section{Conceptual model}

University students have usually different and diverse backgrounds and pre-college experiences, which could influence on students who attend universities and Astin (1999) offered a model based on three elements: input, environment and output. Input is pre-college experiences and personal characteristics, environment means the experience and knowledge that students acquire during the school and output is a dependent variable used to identify changes in students' leadership capacity during their education. This study is important for several reasons: First, it explains how personal characteristics change over time, second, how university influences this change and the third one is the fact that how these changes influence on male and female students. Obviously, this information can improve training programs for university students, especially management students who should have high leadership potential in order to enter job market.

\subsection{Research hypotheses}

1. There is a relationship between university education and student leadership trait potential.

2. There is a relationship between student leadership potential and student's environmental circumstances during the education.

3. There is a relationship between student leadership potential and student's group university activity.

4. There is a relationship between student leadership potential and student participation level in educational programs (curricular).

\section{Methodology}

The data were collected from 116 completed questionnaires of both male and female management students who were enrolled as the first and the last year of education. Fifty of them were male and sixty-six numbers of them were female. The dependent variable for this study, based on the study accomplished by Bandura (1997) and Dugan et al. (2010), was a one-item question asking the respondent to rate her/his leadership capacity by 5-point Likert continuum scale.

Bandura (1997) stated that the people who have some capacities to perform some specific tasks have substantial predictive validity for people's actual task performances. These self-perceptions, which are sensitive to genders and ethnicities, affect one's aspiration, effort, and persistence in achieving the task. Shertzer and Schuh (2004) showed that college students' self-perceived capacity in leadership was closely correlated with their leadership role behaviors (Shertzer \& Schuh, 2004).

This research is a practical study, the method of data collection is descriptive and we use correlation analysis for data analysis. The questionnaire used for this study includes five parts. The first part 
measures leadership potential, the second part evaluates the effect of university education on students, the third part measures environmental and family conditions and students' income, the fourth consists of group and educational activities within the university and finally, the fifth section includes information such as age, gender and educational background. The validity of the questionnaire, which was designed regarding to the similar studies in other countries (Pascarella \& Terenzini, 2005) confirmed by experts opinions.

Cronbach's alpha was used to measure the reliability test; the 0.91 rate of it has indicated a high validity of questionnaire. We used Morgan Table for attaining sample size. From 160 distributed questionnaires, 116 completed questionnaires were returned. From this number 55 people were male and 61 ones were female. In order to describe data, statistical appropriate methods such as frequency, standard deviation, measures of central tendency were used.

To verify the hypothesis, we used Pearson correlation coefficient, variance analysis and the stepwise regression method. Summary statistics of both genders are given in Table 1. T-test was used in order to compare dependent variables of two genders. As the value of the $t(t=2.364)$ at this level $(\mathrm{P} \leq 0.018)$ is significant, the leadership trait potential is different for two genders. Thus, the average of leadership trait potential for male students was higher than females.

Table 1

Summary statistics of both genders

\begin{tabular}{lccc}
\hline Variables & Gender & Mean & Standard deviation \\
\hline \multirow{2}{*}{ Leadership trait potential } & Female & 62.31 & 14.16 \\
& male & 81.76 & 17.12 \\
\multirow{2}{*}{ University education } & Female & 46.63 & 10.30 \\
\multirow{2}{*}{ Environmental circumstances } & male & 58.63 & 8.16 \\
& Female & 63.21 & 6.13 \\
\multirow{2}{*}{ Group activities } & male & 52.21 & 8.76 \\
\multirow{2}{*}{ Educational programs (curricular) } & Female & 29.35 & 8.92 \\
& male & 45.26 & 6.32 \\
& Female & 37.43 & 7.24 \\
\hline
\end{tabular}

For testing the first hypothesis (There is a relationship between university education and student leadership trait potential) Pearson correlation and regression analysis were used. The results of Table 2 show that there was a significant positive relationship between university education and leadership trait potential. (In $\mathrm{P} \leq 0.001$ ) so the first hypothesis is confirmed $(\mathrm{n}=116$, Beta $=0.38$ ).

Table 2

Regression analysis between variables

\begin{tabular}{llccccc}
\hline Predictor & Variable & $\mathrm{B}$ & $\mathrm{Beta}$ & $\mathrm{R}^{2}$ & $\mathrm{t}$ & $\mathrm{P}$-value \\
\hline University education & Leadership trait potential & 0.22 & 0.38 & 0.11 & 3.8 & 0.001 \\
Environmental circumstances & Leadership trait potential & 0.05 & 0.10 & 0.02 & 1.27 & 0.19 \\
Group activities & Leadership trait potential & 0.11 & 0.31 & 0.09 & 4.1 & 0.001 \\
Educational programs (curricular) & Leadership trait potential & 0.18 & 0.35 & 0.15 & 3.2 & 0.001 \\
\hline
\end{tabular}

According to the results of Table 2, there is not a significant correlation between environmental circumstances and Leadership trait potential, (Beta $=0.10, \mathrm{P} \leq 0.018$ ). Thus, the second hypothesis is not confirmed. There is a significant correlation between group activities and leadership trait potential, (Beta=0.31, $\mathrm{P} \leq 0.001)$ and the third hypothesis is confirmed. There is a significant correlation between Leadership trait potential and student participation level in educational programs (curricular), (Beta=0.35, $\mathrm{P} \leq 0.001$ ). Therefore, the forth hypothesis is confirmed too. 


\section{Conclusion}

Results from the current study clarify that university education has influences on leadership capacity among male and female students, although, this effect is greater among male students. This research showed that there was not a relationship between environmental circumstances and leadership trait potential. However, it should be considered that the word "environmental circumstances" encompasses many factors but here it contains only financial, family and social factors. The confirmed relationship between student participation in group activities and educational programs (curricular) with the leadership trait potential is consistent with previous research in other countries. As similar studies in other countries show different and the same results for leadership capacity in both genders, culture should be considered as an effective factor. Thus, the use of culture as a moderating factor is suggested for future research in this area.

\section{Acknowledgment}

The authors would like to thank the anonymous referees for constructive comments on earlier version of this work.

\section{References}

Afjeh, A.A. (2006). Philosophical principles and theories of leadership and organizational behavior. The organization of reading and writing Humanities books of Universities (Samt).

Astin, A. W. (1999). Student involvement: A developmental theory for higher education. Journal of College Student Development, 45(5), 518-529.

Avolio, B. (2005). Executive summary: 100 year review of leadership intervention research: Briefings report 2004-01, Gallup Leadership Institute. Kravis Leadership Institute, Leadership Review, 5, 7-13.

Boatwright, K. J., \& Egidio, R. K. (2003). Psychological predictors of college women's leadership aspirations. Journal of College Student Development, 45(5), 653-669.

Bandura, A. (1977). Self-efficacy: The exercise of control. New York: W.H. Freeman.

Dugan, J. P., \& Komives, S. R. (2010). Influences on college students' capacities for socially responsible leadership. Journal of College Student Development, 51, 525-549.

Dunkel, N., Bray, K., \& Wofford, A. (1998). Training and raising awareness in career knowledge. Paper presented at the Gainesville: Division of Housing, University of Florida.

Eagly, A. H., \& Carli, L. L. (2007). Through the labyrinth: The truth about how women become leaders Boston, MA: Harvard Business School Press.

Huang, Y., \& Chang, S. M. (2004). Academic and curricular involvement: Their relationship and the best combinations for student growth. Journal of College Student Development, 45(4), 391-406.

Hardy, M. A. (1993). Regression with dummy variables. Newbury Park, CA: Sage.

Karnes, F. A., \& Bean, S. M. (1 999). Lead the way to leadership education. Education Digest, 64, 62-65.

Komives, S. R., Owen, J. E., Longerbeam, S. D., Mainella, F. C., \& Osteen, L. (2005). Developing a leadership identity: A grounded theory. Journal of College Student Development, 46(6), 593-611.

MacKinnon-Slaney, F. (1993). Theory to practice in curricular activities: A new model for student involvement. College Student Affairs, 12(2), 35-40.

Mirkamali, M. (2009). Management and leadership.( Seytaroon).

Moghaddas Pour, S., Bakhshi Zadeh, A., \& Barati, E. (2012). An empirical study to measure the relationship between management style and conflict management. Management Science Letters, 2(6), 2249-2254.

Nemati, E. (2012). Cultural management and government role. Management Science Letters, 2(5), $1717-1720$.

Pascarella, E. T., \& Terenzini. (2005). How college affects students: A third decade of research. San Francisco. 
1432

Pascarella, E. T., \& Terenzini. (2005). How college affects students: A third decade of research. San Francisco.

Shertzer, J. E., \& Schuh, J. H. (2004). College student perceptions of leadership: Empowering and constraining beliefs. NASPA Journal, 42(1), 111-131.

Thompson, M. D. (2006). Student leadership progress development: An assessment of contributing college resources. Journal of College Student Development, 47(3), 343-350. 